\title{
Biocompatibilidade dos materiais em Ortodontia: mito ou realidade?
}

\author{
Luciane Macedo de Menezes*, Maria Perpétua Mota Freitas**, Tatiana Siqueira Gonçalves***
}

\begin{abstract}
Resumo
O objetivo deste trabalho é apresentar uma revisão sobre os conceitos relacionados à biocompatibilidade dos materiais empregados em Ortodontia. Fatos relacionados às reações de hipersensibilidade aos diversos materiais ortodônticos são discutidos, sendo apresentadas as condutas recomendáveis nestas situações.
\end{abstract}

Palavras-chave: Ortodontia. Biocompatibilidade. Hipersensibilidade. Alergia. Materiais ortodônticos.

\section{INTRODUÇÃO}

É notável, nos últimos anos, uma crescente preocupação com a biocompatibilidade dos materiais odontológicos. Não se sabe se esse fato está associado a um aumento real na frequência de alergia aos materiais ou a um maior cuidado com os efeitos colaterais provocados pelos mesmos ${ }^{77}$. Como nenhum material dentário é absolutamente seguro, sua seleção deve ser baseada na garantia de que os benefícios se sobreporão aos riscos biológicos ${ }^{4}$.

Na maioria dos casos em Ortodontia, as reações de hipersensibilidade apresentam manifestações locais, podendo, eventualmente, causar desordens sistêmicas. Com isso, a preocupação em relação à segurança e saúde geral do paciente tem sido objeto de estudo na literatura, uma vez que grande parte dos aparelhos e dispositivos utilizados na especialidade é composta por elementos químicos relacionados a alterações no sistema imune.

O objetivo dos autores com este artigo é apresentar os princípios básicos da biocompatibilidade dos materiais odontológicos, bem como sugerir condutas clínicas relacionadas a reações adversas a alguns materiais de uso rotineiro na prática ortodôntica.

\section{Afinal, o que significam os termos biocompatibilidade, toxicidade, alergia e hipersensibilidade?}

Para melhor entender as reações biológicas frente ao uso dos diversos materiais, o cirurgiãodentista deve conhecer os conceitos de biocompatibilidade, toxicidade, alergia e hipersensibilidade, a fim de compreender as condições de alguns pacientes que apresentam alterações no sistema imune.

A biocompatibilidade ocorre quando os tecidos entram em contato com um determinado material e não manifestam qualquer tipo de experiência tóxica, irritante, inflamatória, alérgica ou de fundo mutagênico ou carcinogênico ${ }^{40}$. A ocorrência de qualquer reação adversa é chamada de toxicidade. Para a biocompatibilidade de um

\footnotetext{
* Mestre e doutora em Ortodontia pela UFRJ. Professora adjunta de Ortodontia da Faculdade de Odontologia da PUCRS.

** Mestre em Ortodontia e Ortopedia Facial e doutora em Materiais Dentários pela PUCRS.

*** Mestre e doutoranda em Ortodontia e Ortopedia Facial pela PUCRS
} 
determinado material é necessária uma resposta adequada do hospedeiro, o que, em Odontologia, significa a não-ocorrência de reações adversas, ou a ocorrência de reações adversas toleráveis, do organismo frente a esse material ${ }^{70}$.

A citotoxicidade, ou avaliação da toxicidade em cultura de células, é um fenômeno in vivo complexo, o qual pode manifestar um amplo espectro de efeitos, desde uma simples morte celular até aberrações metabólicas, nas quais não ocorre morte celular, mas apenas alterações funcionais ${ }^{20}$. A genotoxicidade avalia o dano ao DNA e é, geralmente, utilizada para auxiliar na investigação de potenciais efeitos, benéficos ou danosos, de diferentes agentes ${ }^{20}$.

As reações de hipersensibilidade são desordens que têm origem numa resposta imune que se torna exagerada ou inapropriada, ocasionando lesões sobre células ou tecidos normais do organismo, enquanto alergia significa uma hipersensibilidade específica adquirida do sistema imune, tanto de uma fonte exógena quanto endógena ${ }^{72}$.

\section{Como saber se um paciente é alérgico a um determinado material?}

A realização da anamnese - um dos elementos essenciais de diagnóstico em Ortodontia - deve fazer parte da rotina da primeira consulta. A anamnese deve conter um breve histórico da saúde geral do paciente, assim como um bom questionário, que abranja também perguntas relacionadas à ocorrência de alergias e reações de hipersensibilidade. Assim, o primeiro passo é incluir, na consulta inicial, algumas perguntas relacionadas a alergias: "Você apresenta/apresentou algum tipo de reação alérgica medicamentos, metais, borracha, resinas, ou outro produto ou material?".

Tendo o paciente relatado algum tipo de alergia, o segundo passo seria encaminhá-lo a um médico (alergista ou dermatologista) para avaliação mais aprofundada. O médico poderá requerer a realização de um Teste de Contato, para confirmação das respostas alérgicas ${ }^{13}$. Esses testes têm como objetivo avaliar a resposta da pele frente a diferentes substâncias. Porém, questiona-se a validade dos mesmos, pela possibilidade de apresentarem "falsos positivos" e de sensibilizarem o paciente.

Os procedimentos para a realização do teste de contato estão descritos nas figuras 1 e 2 .

Vários trabalhos utilizando esse teste foram publicados, procurando-se determinar a incidência da hipersensibilidade ao níquel, conforme se pode observar no quadro 1 .

\section{Quais os materiais de uso ortodôntico mais frequentemente associados às reações alérgicas?}

Dentre os materiais mais frequentemente associados às reações alérgicas podem ser citados os elásticos derivados do látex, resinas acrílicas e compostas, bem como as diversas ligas metálicas presentes nos acessórios e fios empregados nos tratamentos ortodônticos.

\section{Metais}

Os metais são considerados as toxinas mais antigas. Inicialmente, havia grande preocupação com os efeitos agudos determinados pelos íons metálicos, entretanto, esses efeitos são considerados
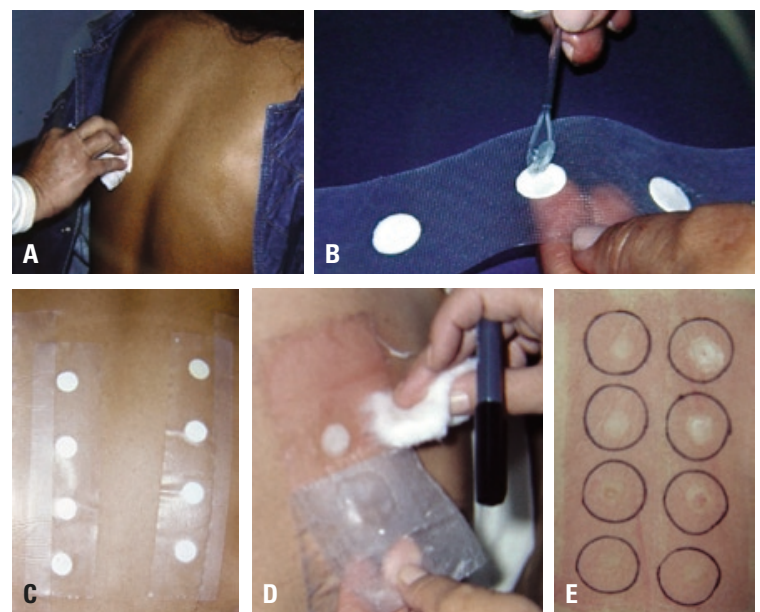

FIGURA 1 - A) Seleção e limpeza da região com algodão embebido em álcool ou éter; B) preparação das substâncias sobre os contensores; C) posicionamento dos contensores; D) remoção dos contensores;

E) delimitação da área para posterior leitura do teste de contato. 

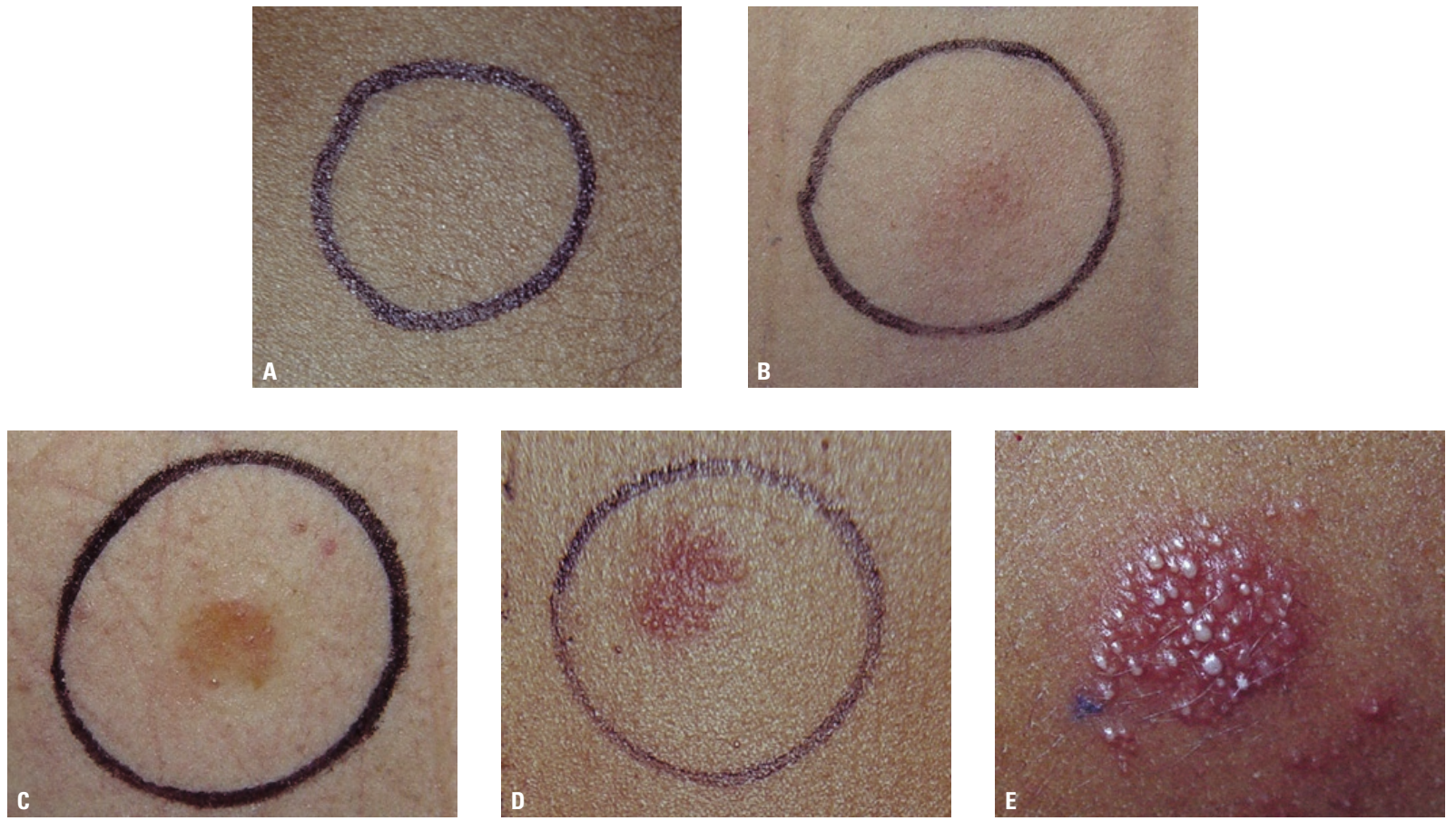

FIGURA 2 - A) Sem reação: negativo. B) Eritema: negativo. C) Eritema e pápulas: positivo. D) Eritema, pápulas e vesículas: positivo. E) Edema com vesículas: positivo.

\begin{tabular}{|c|c|c|c|c|}
\hline autores & gênero, idade do paciente & aparelho utilizado & localização da lesão & sinais e sintomas \\
\hline Bishara $^{12}$ (1995) & masculino, 12 anos & contenção com solda & mucosa bucal e bochechas & irritação e inflamação \\
\hline Al- Waheidi³ (1995) & masculino, 14 anos & $\begin{array}{l}\text { aparelho fixo } \\
\text { níquel-titânio }\end{array}$ & lábios e mucosa bucal & queimação e ulcerações \\
\hline Menezes et al. ${ }^{56}(1997)$ & feminino, 27 anos & $\begin{array}{l}\text { aparelho } \\
\text { extrabucal }\end{array}$ & pescoço & $\begin{array}{c}\text { urticária, irritação e } \\
\text { vesículas }\end{array}$ \\
\hline Kerosuo, Kanerva ${ }^{42}$ (1997) & masculino, 14 anos & aparelho extrabucal & lábios & vesículas \\
\hline de Silva, Doherty ${ }^{17}(2000)$ & masculino, 12 anos & $\begin{array}{l}\text { aparelho fixo } \\
\text { níquel-titânio }\end{array}$ & $\begin{array}{l}\text { região bucal, orbital e } \\
\text { couro cabeludo }\end{array}$ & $\begin{array}{c}\text { eczemas peribucais, } \\
\text { perda de cabelo }\end{array}$ \\
\hline Counts et al. ${ }^{16}$ (2002) & feminino, 11 anos & barra transpalatina & mucosa bucal & hipertrofia gengival \\
\hline Mancuso, Berdondini ${ }^{52}$ (2002) & feminino, 13 anos & $\begin{array}{l}\text { aparelho removível } \\
\text { aço inoxidável }\end{array}$ & região periorbital & $\begin{array}{c}\text { dermatite nas pálpebras e } \\
\text { conjuntivite }\end{array}$ \\
\hline
\end{tabular}

QUADRO 1 - Trabalhos que mostraram casos clínicos de reações de hipersensibilidade aos aparelhos ortodônticos (Fonte: WESTPHALEN², 2006).

incomuns, devido aos padrões ambientais e ocupacionais que regem as regulamentações legais. Dessa forma, tem aumentado o interesse acerca das alterações crônicas ou de longo prazo, visto que a relação causa-efeito nem sempre é imediatamente perceptível, podendo ter efeitos subclínicos ${ }^{45}$.

A determinação da biocompatibilidade representa um processo complexo e pode ser avaliada por testes de toxicidade in vitro (citotoxicidade e genotoxicidade) e in vivo, utilizando diversas metodologias regulamentadas e padronizadas. Nesse sentido, a especificação de padrões da American Dental Association (ADA), aprovada pelo American National Standards Institute, denominada ANSI/ADA ${ }^{1}$, em seu documento ANSI/ADA Tipo 5 versa sobre a padronização dos materiais 
utilizados em Ortodontia ${ }^{20}$. Para avaliação biológica, os testes são geralmente divididos em testes iniciais de toxicidade; testes secundários, relacionados à toxicidade tecidual local, e testes de aplicação ou pré-clínicos ${ }^{20}$.

Embora as interações entre uma liga metálica e os tecidos possam ocorrer de diversas formas, a liberação de elementos da liga na cavidade bucal é o foco primário dos estudos, visto que efeitos biológicos adversos - como alergias e inflamação - têm sido atribuídos a esse processo, em virtude da liberação iônica advinda dos aparelhos ortodônticos poder, hipoteticamente, aumentar a concentração dos íons no corpo, acima da concentração de ingestão ou exposição aos metais pelo meio ambien$\mathrm{te}^{87}$. Outro ponto de fundamental importância na avaliação do emprego de metais pesados na Ortodontia é o seu potencial genotóxico, citotóxico e carcinogênico, uma vez que elementos metálicos como o níquel e o cromo apresentam resultados positivos relacionados à toxicidade genética.

Estudos in vivo mostraram que metais como o níquel e o cobalto, liberados de aparelhos ortodônticos, podem causar quebras no DNA de células da mucosa bucal ${ }^{21,87}$. Em 2008, Westphalen et al..$^{90}$ avaliaram a toxicidade genética associada ao uso de aparelhos ortodônticos e observaram, através do ensaio cometa, que houve um incremento no nível de dano primário do DNA, embora não significativo, 10 dias após a montagem do aparelho ortodôntico.

Um dos pontos determinantes da biocompatibilidade das ligas metálicas em Odontologia é a resistência à corrosão ${ }^{85}$. A corrosão representa uma perda de metal ou sua conversão num óxido. No ambiente úmido da cavidade bucal, todas as ligas sofrem corrosão, pelo menos em alguma extensão ${ }^{77}$. A saliva é um ambiente ativo de constituintes orgânicos, íons e não-eletrólitos que são arrastados constantemente contra os anéis, braquetes e arcos. As diferenças galvânicas entre a saliva e os metais podem dar início a reações eletroquímicas, gerando a corrosão galvânica, que geralmente se manifesta pelo processo corrosivo acelerado dos metais menos nobres (ânodos) ${ }^{33}$. O aparelho ortodôntico representa um exemplo típico ${ }^{66}$, cuja corrosão pode causar sérias implicações clínicas que variam da perda de dimensão - resultando em forças menores aplicadas aos dentes - à falha (quebra) do aparelho em regiões de tensão. Além disso, a produção de possiveis produtos tóxicos da corrosão dos aparelhos e sua absorção pelos tecidos circundantes é indesejável ${ }^{80}$.

Diversos são os fatores que podem interferir no processo de liberação iônica de uma liga: o método de fabricação, o tipo de liga e as características superficiais do acessório; as características do meio em que a peça está inserida, como composição, temperatura, $\mathrm{pH}$, flora bacteriana, atividade enzimática e presença de proteínas ${ }^{75}$; além de fatores como o uso (envelhecimento) da liga, que pode estar sujeita a adversidades como estresse, tratamento térmico, reciclagem ou reutilização de componentes, dentre outros ${ }^{35}$. Acrescenta-se que a tendência de liberação de íons está, muitas vezes, associada à sua instabilidade ou labilidade. Para Wataha, Lockwood e Schedle ${ }^{86}$, cobre, níquel e gálio são elementos que apresentam essas características, as quais podem ser alteradas pela presença de outros elementos na liga.

$\mathrm{Na}$ literatura, é grande a diversidade de trabalhos com enfoque na liberação de íons metálicos de braquetes ortodônticos - principalmente ferro, cromo e níquel, que representam os principais produtos da corrosão do aço inoxidável $1^{8,19,44,53,64,74}$. Entretanto, de acordo com o International Register of Potentially Toxic Chemical of United Nations Environment Program, outros íons metálicos, presentes na solda de prata utilizada na aparelhagem ortodôntica - como o cádmio, o cobre e o zinco - podem ser liberados na cavidade bucal e já são considerados produtos químicos potencialmente perigosos, sendo incluídos na lista de substâncias e processos considerados de grande risco para a vida humana. Em estudo sobre a liberação iônica e citotoxicidade da solda de prata, Freitas ${ }^{25}$ observou 
alta toxicidade desse material para fibroblastos, denotando alterações na adesão, proliferação e crescimento celular, bem como liberação significativa dos íons constituintes da solda de prata, com concentrações elevadas imediatamente após a instalação do aparelho, em ordem decrescente, de cobre, prata, zinco e cádmio, representando risco de absorção e retenção desses íons pelo organismo humano.

Em decorrência da liberação iônica, a utilização de aparelhos ortodônticos tem sido associada a algumas reações de hipersensibilidade. Dentre os metais, o níquel tem sido considerado uma das causas mais comuns da dermatite de contato ${ }^{10}$. Infelizmente, a associação com o níquel faz parte da vida moderna e, devido à onipresença do mesmo, as reações a esse metal apareceram com muito mais frequência na população em geral, e não são mais exclusivas dos funcionários da indústria ${ }^{57}$, como era observado anteriormente. O cromo também está relacionado a reações de hipersensibilidade ${ }^{2}$, sendo apontado como a segunda causa mais frequente de dermatite de contato $^{64}$. Em média, $8 \%$ da população é sensível a esse metal ${ }^{84,90}$.

As reações alérgicas podem ser divididas em tipos I, II, III e IV ${ }^{58}$, sendo que, na Odontologia, de modo geral, ocorrem as do tipo IV, que acontecem após uma sensibilização prévia e reexposição do indivíduo ao alérgeno. A resposta regride após remoção do agente causador e reinicia quando os tecidos são novamente expostos ao mesmo ${ }^{18}$. Tais reações podem ser comprovadas através de testes de contato, que são empregados rotineiramente por dermatologistas e têm como objetivo avaliar a resposta da pele frente a diferentes substâncias.

Segundo Schriver et al. ${ }^{71}$, a reação alérgica ao níquel é derivada do timo, uma imunidade celular dependente de linfócito, ou seja, reação de hipersensibilidade do tipo IV ${ }^{11}$. A persistência deste tipo de reação está associada à memória do linfócito, que é capaz de reconhecer antígenos específicos muitos anos após o primeiro contato ${ }^{71}$.
Por ser o níquel um hapteno, pode ligar-se a proteínas e agir como um antígeno, mas, para agir como tal, o íon precisa ser liberado da liga, fazendo-se necessária uma exposição anterior ao alérgeno. A aparência clínica é de edema, eritema e vesículas. Histologicamente, o epitélio apresenta edema inter e intracelular, com formação de vesículas, sendo também encontradas várias combinações de células mononucleares, neutrófilos e eosinófilos. A dessensibilização é difícil, pois a reação não responde ao anti-histamínico, mas somente ao corticoide. Entretanto, para a continuidade da reação, o antígeno deve estar presente ${ }^{65}$.

A literatura descreve alguns casos clínicos de reações, na pele ou mucosa, associadas à sensibilidade ao níquel (Quadro 2 ). Pesquisas mostram que a dermatite de contato está relacionada ao contato com joias, óculos e relógios ${ }^{13,37,39,43}$ e tem incidência significativa - de 8 a 30\% da população em geral $^{32}$ (1:1000, segundo GRIMAUDO $\left.{ }^{31}\right)$, sendo maior nas mulheres que nos homens $s^{31,37,39,44,55,60}$. Outros fatores têm sido associados ao desenvolvimento de sensibilidade ao níquel, como: irritação mecânica, maceração da pele, aumento da temperatura ambiente, aumento da intensidade e duração da exposição. Fatores genéticos também têm influência na aquisição e regulação da resposta imune, apesar deste fato ainda não ser conclusivo ${ }^{10}$.

Menezes et al. ${ }^{56}$ publicaram o caso de uma paciente que demonstrou reação alérgica à parte metálica da tala cervical do aparelho extrabucal. Foi relatada urticária e irritação da pele do pescoço. Clinicamente, foi observada uma área eritematosa com vesículas no pescoço, uma lesão de cada lado, correspondendo em tamanho e localização das partes metálicas da tala do aparelho extrabucal (Fig. 3A, B, C). A análise do histórico clínico da paciente revelou que a mesma apresentava alergia a brincos que não fossem de ouro, provocando inflamação local e descamação da pele após o seu uso. A lesão foi diagnosticada como sendo uma dermatite de contato. O tratamento realizado consistiu na remoção do estímulo, 


\begin{tabular}{|ccccc}
\hline autores & $\begin{array}{c}\text { número de indivíduos na } \\
\text { população estudada }\end{array}$ & $\begin{array}{c}\text { incidência de } \\
\text { resultado positivo (\%) }\end{array}$ & $\begin{array}{c}\text { incidência de resultado } \\
\text { positivo nas mulheres (\%) }\end{array}$ & $\begin{array}{c}\text { incidência de resultadó } \\
\text { positivo nos homens (\%) }\end{array}$ \\
\hline Blanco-Dalmau et al..$^{13}(1984)$ & 403 & 28,5 & 31,9 & 20,7 \\
\hline Feasby et al. ${ }^{22}(1988)$ & 700 & 8,1 & 9,5 & 6,8 \\
Bass et al. ${ }^{10}(1993)$ & 29 & 18,5 & 18,5 & 0 \\
Kerosuo et al. ${ }^{43}(1996)$ & 700 & 19 & 30 & 3 \\
Stenman, Bergman ${ }^{77}(1989)$ & 151 & 14 & 95 & 5 \\
Jones et al. ${ }^{38}(1986)$ & 100 & 22 & 20 & 2
\end{tabular}

QUADRO 2 - Resumo dos resultados de alguns trabalhos publicados na literatura, onde foram realizados testes de contato para verificar a incidência de hipersensibilidade ao níquel.
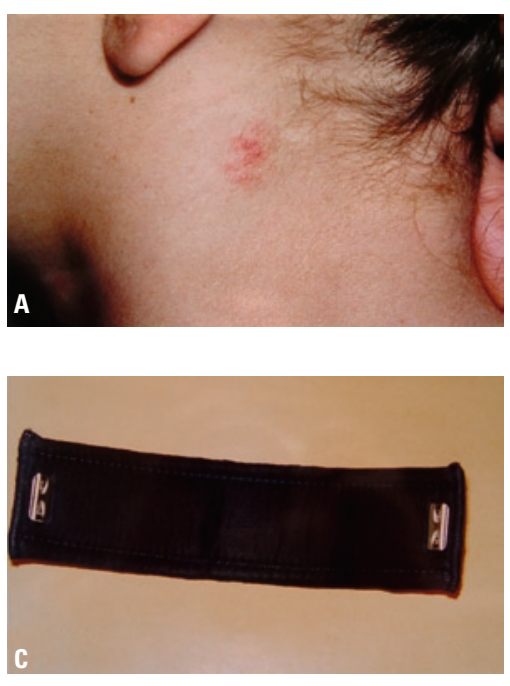

FIGURA 3 - A) Dermatite de contato em decorrência do uso da tala do aparelho extrabucal. B, C) Tala utilizada. D) Remissão dos sinais após a troca da tala, sem contato do metal com a pele (Fonte: MENEZES et al. $\left..^{56}, 1997\right)$.

ou seja, troca da tala cervical por uma onde a parte metálica não entrasse em contato com a pele. Quinze dias após o diagnóstico e tratamento, a paciente retornou sem nenhum sinal de reação alérgica (Fig. 3D).

Outro fator que tem gerado preocupação é o uso de aparelhos ortodônticos metálicos em indivíduos hipersensíveis. Esses aparelhos são, geralmente, feitos de aço inoxidável austenítico, que contem cerca de $18 \%$ de cromo e $8 \%$ de níquel ${ }^{43}$. Alguns fios metálicos com propriedades elásticas podem conter mais de $50 \%$ de níquel ${ }^{43}$, como é o caso dos fios de níquel-titânio, que contém aproximadamente $70 \%$ de níquel ${ }^{10}$.
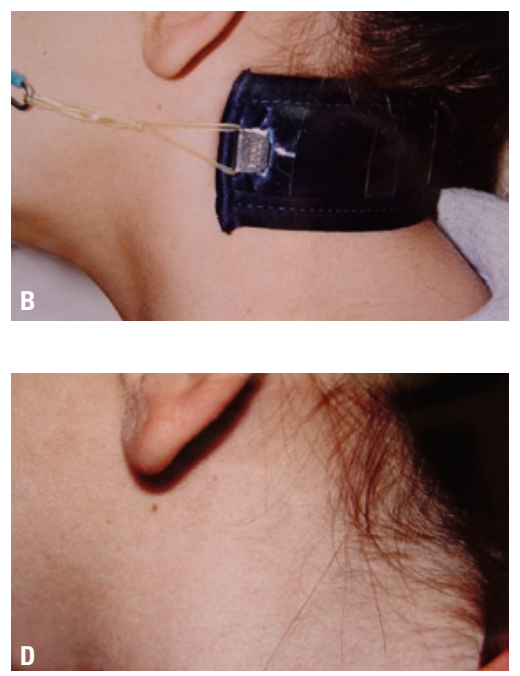

Kerosuo, Moe e Kleven ${ }^{44}$ observaram in vitro que parece ocorrer liberação detectável de níquel e de cromo dos aparelhos ortodônticos, sendo a quantidade maior em condições dinâmicas. Mesmo assim, a quantidade estimada de liberação de níquel de um aparelho ortodôntico completo é menor que $10 \%$ da quantidade ingerida diariamente na dieta $^{8}$, sendo considerada negligenciável do ponto de vista toxicológico ${ }^{44}$. Barrett, Bishara e Quinn ${ }^{8}$ ressaltam que ainda precisa ser determinado quanto destes produtos de corrosão é realmente absorvido pelo paciente. A questão é se a quantidade de metal liberada é exposta suficientemente às células imunocompetentes para 
sensibilizar um indivíduo ou para manter uma reação num indivíduo previamente sensibilizado pela substância ${ }^{77}$. Acredita-se que as quantidades liberadas podem ser de considerável importância para os indivíduos com alto grau de sensibilidade ao níque ${ }^{44}$. Portanto, o clínico deve ser cauteloso, pois a liberação de níquel e cromo dos anéis ortodônticos pode sensibilizar os pacientes a esses metais e provocar reações de hipersensibilidade em pacientes com histórico prévio de sensibilidade aos mesmos ${ }^{64}$. Com base nas evidências disponíveis e riscos em potencial que podem ser antecipados com a exposição intrabucal de ligas contendo níquel, o Conselho de Materiais, Instrumentos e Equipamentos Dentários dos EUA, em 1982, contra-indicou o uso desses materiais em pacientes sensíveis ou em pacientes supostamente sensíveis. Para o Conselho, é de responsabilidade do dentista conhecer a origem e constituintes das ligas utilizadas na clínica, especialmente quanto à presença ou ausência de níquel, e informar o paciente quando necessário - sendo uma condição imposta para aceitação das ligas contendo níquel a apresentação de um rótulo como alerta contendo a seguinte declaração: "CUIDADO: esta liga contém níquel e não deve ser usada por indivíduos sensiveis a esse metal" ${ }^{57}$.

Na Alemanha, o Departamento Federal de Saúde recomendou que não se utilizem acessórios contendo níquel em Ortodontia. Assim, os fabricantes estão produzindo braquetes livres de níquel, utilizando novas ligas ${ }^{63}$. O titânio, apesar de ser muitas vezes mais caro do que o aço inoxidável, vem sendo utilizado para confecção de acessórios. Os braquetes de titânio puro apresentam maior tolerância tecidual, maior biocompatibilidade e resistência, quando comparados aos de aço inoxidável ${ }^{33}$. Os braquetes denominados "nickel-free", geralmente compostos por cromo e cobalto, também podem ser empregados como material alternativo para pacientes com sensibilidade ao aço. Nesse contexto, não se pode deixar de ressaltar que os braquetes estéticos, sejam eles de cerâmica ou policarbonato, também servem como alternativa para pacientes com alergia ao níquel. Está disponível no mercado brasileiro um fio ortodôntico estético totalmente livre de metais - pois é um polímero - e, da mesma forma, serve como uma alternativa, nos estágios iniciais de tratamento, para pacientes com alergia ao níquel. É de extrema importância ressaltar também que o uso de acessórios reciclados não é recomendado, uma vez que esse tipo de material apresenta uma maior liberação de íons para o ambiente bucal, quando comparada à dos braquetes novos ${ }^{35}$.

\section{Látex}

É alta a prevalência da hipersensibilidade ao látex, em virtude da sua ampla utilização em produtos manufaturados contendo borracha ${ }^{78}$. De acordo com Weiss e Hirshman ${ }^{88}$, o advento da vulcanização - por Charles Goodyear, em 1839 - levou à aplicação do látex em mais de 40.000 itens, tais como: produtos odontológicos (luvas, máscaras, borrachas de isolamento e acessórios ortodônticos), equipamentos médicos (luvas, catéteres, tubos, implantes e próteses), luvas de uso doméstico, balões e bolas, preservativos, adesivos, chupetas, carpetes, calçados, capachos e equipamentos esportivos ${ }^{50}$.

$\mathrm{Na}$ literatura, diversos são os relatos de reações ao látex. Em geral, aparecem em jovens, sendo muito frequentes nos adultos em profissões de risco, como Odontologia e outras profissões da área de Saúde, com maior prevalência em mulheres ${ }^{50}$. Segundo Fisher ${ }^{24}$, 7\% dos profissionais (médicos, enfermeiras e dentistas) manifestam uma reação alérgica tardia (dermatite de contato), enquanto $3 \%$ mostram uma reação imediata. Devido ao grande número de relatos de reações adversas ao látex, em 1993 foi regulamentado que os rótulos de produtos médicos contendo látex devem indicar sua presença.

Em estudo realizado por Conde-Salazar et al. ${ }^{15}$, foram avaliados 7.000 pacientes durante um período de 10 anos (1978-1988). Destes, 4.860 
foram submetidos a testes e um total de $14,7 \%$ apresentou uma ou mais reações positivas aos aditivos da borracha. Especificamente na área odontológica, um estudo feito com base em questionários distribuídos para dentistas na Inglaterra e País de Gales revelou que 135 dos entrevistados observaram reações adversas ao uso de luvas de látex pelos dentistas, bem como em um ou mais de seus pacientes ${ }^{14}$.

O primeiro passo para o diagnóstico de alergia ao látex é registrar o histórico clínico do paciente, pesquisando eventos prévios, associando ao teste cutâneo usando látex e/ou seus extratos ${ }^{50}$. Faz-se prudente iniciar a pesquisa pelo teste radioalergosorvente ("RAST") e, se negativo, proceder ao teste de contato ${ }^{88}$. A exposição repetida ao látex de borracha natural é essencial para o desenvolvimento da sensibilidade ${ }^{50}$. Imediatamente após o contato direto com esse material ou inalação de alérgenos transportados pelo ar - por exemplo o pó das luvas -, uma pessoa sensibilizada pode experimentar uma série de reações, tais como corrimento nasal, conjuntivite, dificuldade de deglutição, dermatite de contato, urticária generalizada, asma e anafilaxia, angioedema, rinite e taquicardia ${ }^{50,88}$. Para Barton $^{9}$, a proteína de borracha natural é o alérgeno de sensibilização, embora a proteína específica não tenha sido isolada.

O látex é basicamente composto de moléculas grandes, que não parecem provocar alergias, sendo o poli-isopreno o principal constituinte da borracha, além de proteínas, que perfazem um total de 2 a $3 \%$ do produto final ${ }^{88}$. Por outro lado, substâncias de baixo peso molecular, como aditivos, antioxidantes e vulcanizadores - comumente utilizados na manufatura da borracha e responsáveis pelas propriedades finais desejadas - são, muitas vezes, responsáveis pela sensibilização. Esses aditivos são frequentemente liberados da borracha, principalmente luvas e botas, em ambiente morno e úmido.

A prevenção primária da sensibilização ao látex implica em evitar a exposição, fato quase impossível, dado o grande número de produtos utilizados desde a infância (chupetas, calçados, etc). Como prevenção secundária, para evitar reações de hipersensibilidade, deve-se substituir os produtos à base de látex por aqueles que não o contenham ${ }^{50,73}$.

\section{Resinas acrílicas}

As resinas acrílicas são, também, amplamente utilizadas na Ortodontia, nos aparelhos removíveis, de contenção e/ou aparelhos fixos auxiliares. Desde a década de 60, existem relatos de hipersensibilidade às resinas acrílicas, sendo, na grande maioria dos casos, associados à presença de um alto conteúdo de monômero de metilmetacrilato residual. Em função disso, diversos autores procuraram quantificar o conteúdo desse monômero residual $7,23,28,36,41,48,54,69,76,81,82,91,92$. Além do metilmetacrilato, podem-se citar também outros componentes de baixo peso molecular - tais como formaldeído, peróxido de benzoíla e plastificantes como dibutil-ftalato - que podem ser considerados fatores desencadeadores das reações de hipersensibilidade ${ }^{18}$.

Os testes para avaliação de citotoxicidade indicam que as resinas acrílicas quimicamente ativadas apresentam, in vitro, de um modo geral, maior efeito citotóxico, quando comparadas às termopolimerizáveis e fotopolimerizáveis ${ }^{34,41,67}$. Alguns autores sugeriram que quanto maior o tempo de eluição dos seus subprodutos, em especial o monômero residual, menor o efeito citotóxico exercido sobre as linhagens celulares testadas ${ }^{29,41,47}$. Com isso, algumas manobras clínicas, executadas após a confecção dos aparelhos em resina acrílica, foram sugeridas, no intuito de reduzir esse efeito (Quadro 3).

Quais as reações causadas pelas resinas acrílicas?

As reações de hipersensibilidade causadas pelas resinas acrílicas limitam-se a manifestações locais, incluindo dor, edema e eritema nos locais 


\begin{tabular}{|c|c|c|}
\hline autores & ano & manobra sugerida \\
\hline Nunes de Mello et al. ${ }^{62}$ & 2003 & realização de ciclo adicional de polimerização em microondas ou água aquecida \\
\hline Lee, Lai, $\mathrm{Hsu}^{49}$ & 2002 & polimerização em ambiente aquoso \\
\hline Koutis, Freeman ${ }^{46}$ & 2001 & realização de ciclo de polimerização adicional \\
\hline Rose et al. ${ }^{67}$ & 2000 & armazenamento em água por 72 horas antes da entrega do aparelho \\
\hline Kedjarune, Charoenworaluk, Koontongkaew ${ }^{41}$ & 1999 & $\begin{array}{l}\text { armazenamento em água por } 24 \text { horas antes da entrega do aparelho ao paciente; } \\
\text { manutenção da proporção entre pó e líquido }\end{array}$ \\
\hline Vallittu ${ }^{82}$ & 1996 & $\begin{array}{l}\text { realização de correto polimento mecânico; } \\
\text { utilização de cobertura de resina fotopolimerizável }\end{array}$ \\
\hline Yunus et al. ${ }^{92}$ & 1994 & $\begin{array}{l}\text { realização de ciclo de polimerização em microondas; } \\
\text { polimerização em temperaturas mais elevadas e sob pressão }\end{array}$ \\
\hline Tsuchiya et al. ${ }^{81}$ & 1994 & imersão em água a $50^{\circ} \mathrm{C}$ por uma hora \\
\hline Stafford, Brooks ${ }^{76}$ & 1985 & armazenamento em água até a entrega \\
\hline Lamb, Ellis, Priestley ${ }^{48}$ & 1982 & $\begin{array}{l}\text { manutenção da proporção entre pó e líquido; armazenamento do dispositivo em } \\
\text { resina em temperaturas elevadas; polimerização sob pressão em ambiente aquoso }\end{array}$ \\
\hline McCabe, Basker ${ }^{54}$ & 1976 & realização de ciclo de polimerização adicional \\
\hline Giunta, Zablotsky ${ }^{26}$ & 1976 & armazenamento em água por 36 horas; realização de ciclo em autoclave \\
\hline
\end{tabular}

QUADRO 3 - Manobras sugeridas na literatura para redução do monômero residual (Fonte: GONÇALVES $\left.{ }^{27}, 2005\right)$.
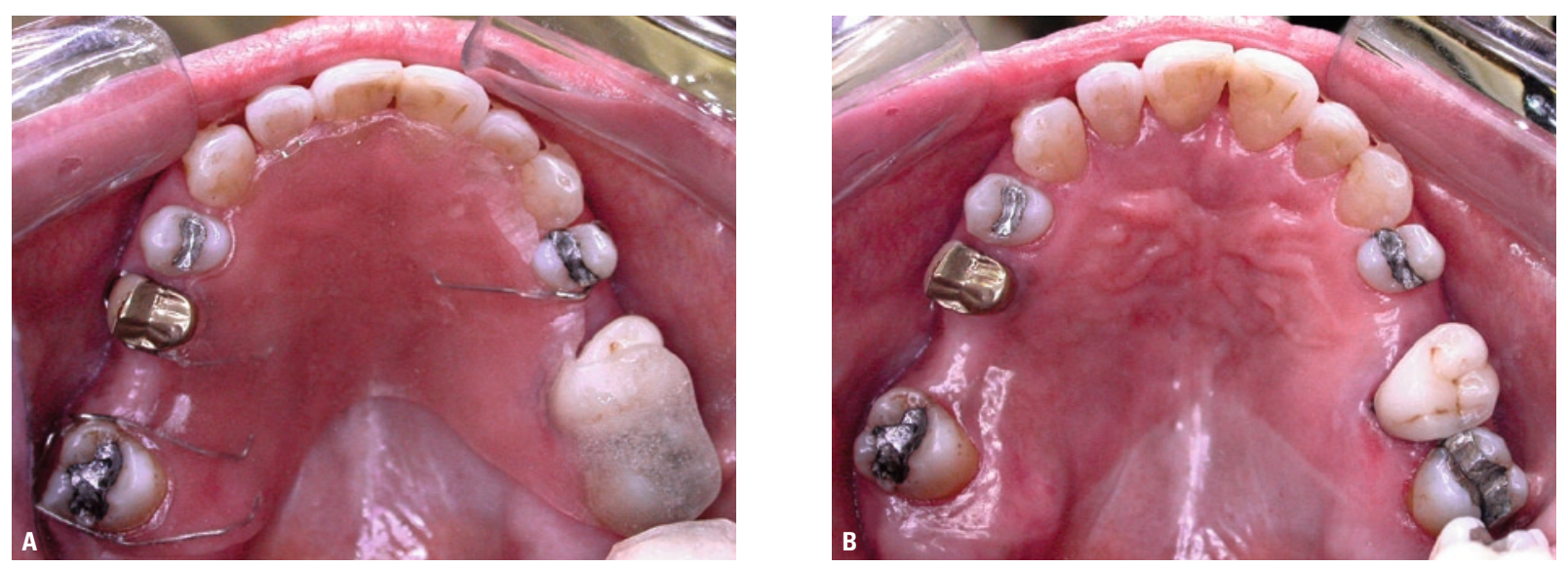

FIGURA 4 - Reação de hipersensibilidade local: A) aparelho de contenção utilizado e B) reação local de eritema sob o aparelho de contenção (Fonte: GONÇALVES et al. $\left.{ }^{30}, 2006\right)$.

de contato (Fig. 4). Entretanto, em alguns casos, podem ocorrer reações de ordem sistêmica, de maior ou menor intensidade, como: sensação de queimação, dificuldade na deglutição, edema nos lábios e urticária ${ }^{30,51,68}$. O quadro 4 mostra uma compilação dos casos de alergia ao acrílico relatados na literatura e a medida para a remissão da hipersensibilidade.

Quando as reações são localizadas, pode-se utilizar medicamentos contendo anti-inflamatórios esteroides, para alívio das reações inflamatórias.
Entretanto, o conforto efetivo só é alcançado após remoção do fator etiológico, o que muitas vezes significa buscar materiais alternativos, para evitar o contato com o material desencadeador da reação de hipersensibilidade ${ }^{30}$. Algumas possibilidades em Ortodontia seriam utilizar aparelhos confeccionados somente com metais ou, nos casos de aparelhos de contenção, substituir por contenções coladas. Além disso, estão disponíveis no mercado internacional as resinas acrílicas fotopolimerizáveis, dificilmente encontradas no mercado brasileiro. 


\begin{tabular}{|c|c|c|c|c|c|}
\hline autor & idade/gênero & tipo de prótese & sinais e sintomas & $\begin{array}{l}\text { sensibilizante/ } \\
\text { alérgeno }\end{array}$ & resolução \\
\hline $\begin{array}{l}\text { Gonçalves et al. }{ }^{30} \\
\qquad(2006)\end{array}$ & $60 \mathrm{a} / \mathrm{fem}$. & $\begin{array}{c}\text { aparelho removível } \\
\text { de contenção orto- } \\
\text { dôntica }\end{array}$ & $\begin{array}{l}\text { dor e eritema local, } \\
\text { sensação de queima- } \\
\text { ção e dificuldade de } \\
\text { engolir }\end{array}$ & $\begin{array}{c}\text { MMA } \\
\text { (teste de contato) }\end{array}$ & $\begin{array}{l}\text { confecção de conten- } \\
\text { ção com fio metálico, } \\
\text { colada aos dentes } \\
\text { com resina composta }\end{array}$ \\
\hline $\begin{array}{l}\text { Tanoue, Nagano, } \\
\text { Matsumura }{ }^{79}(2005)\end{array}$ & $55 a /$ masc. & $\begin{array}{l}\text { prótese parcial } \\
\text { removível em poli- } \\
\text { metilmetacrilato; } \\
\text { prótese em metal e } \\
\text { acrílico }\end{array}$ & $\begin{array}{l}\text { dor, salivação e } \\
\text { ardência bucal }\end{array}$ & $\begin{array}{c}\text { PMMA, polisulfona e } \\
\text { policarbonato } \\
\text { (teste de contato) }\end{array}$ & $\begin{array}{l}\text { confecção de prótese } \\
\text { em uretano dimeta- } \\
\text { crilato }\end{array}$ \\
\hline $\begin{array}{l}\text { Ruiz-Genao et al. }{ }^{68} \\
\qquad(2003)\end{array}$ & 72a / fem. & $\begin{array}{c}\text { prótese total; } \\
\text { prótese total reforça- } \\
\text { da por compósito }\end{array}$ & $\begin{array}{c}\text { edema e ardência nos } \\
\text { lábios }\end{array}$ & $\begin{array}{c}\text { MMA } \\
\text { (teste de contato) }\end{array}$ & $\begin{array}{c}\text { confecção de prótese } \\
\text { em níquel e cromo }\end{array}$ \\
\hline $\begin{array}{l}\text { Koutis, Freeman }{ }^{46} \\
\text { (2001) }\end{array}$ & 71a / masc. & prótese total & $\begin{array}{l}\text { dor, eritema e ardên- } \\
\text { cia bucal }\end{array}$ & $\begin{array}{l}\text { teste de contato } \\
\text { positivo para diversas } \\
\text { resinas e acrilatos }\end{array}$ & $\begin{array}{l}\text { fervura da própria } \\
\text { prótese do paciente }\end{array}$ \\
\hline Auzerie et al. ${ }^{6}(2001)$ & $55 a /$ fem. & $\begin{array}{l}\text { prótese total em resi- } \\
\text { na acrílica termopoli- } \\
\text { merizável }\end{array}$ & erupção liquenoide & $\begin{array}{c}\text { MMA } \\
\text { (teste de contato) }\end{array}$ & $\begin{array}{l}\text { prótese livre de } \\
\text { metilmetacrilato }\end{array}$ \\
\hline $\begin{array}{l}\text { Lunder, Rogl-Butina }{ }^{51} \\
\qquad(2000)\end{array}$ & 49a / fem. & prótese total & urticária & $\begin{array}{c}\text { MMA } \\
\text { (teste de contato) }\end{array}$ & $\begin{array}{l}\text { confecção de prótese } \\
\text { livre de } \\
\text { metilmetacrilato }\end{array}$ \\
\hline Austin, Basker ${ }^{5}$ (1980) & $\begin{array}{l}75 a / \text { fem. } \\
\text { 70a / fem. } \\
\text { 59a / fem. }\end{array}$ & $\begin{array}{l}\text { prótese total em resi- } \\
\text { na acrílica termopoli- } \\
\text { merizável }\end{array}$ & $\begin{array}{l}\text { ardência bucal } \\
\text { dificuldade para } \\
\text { deglutir e dor } \\
\text { ardência bucal }\end{array}$ & MMA & $\begin{array}{l}\text { confecção de nova } \\
\text { prótese em ciclo ideal } \\
\text { de polimerização, com } \\
\text { níveis reduzidos de } \\
\text { monômero }\end{array}$ \\
\hline $\begin{array}{l}\text { Fernström, Öquist }{ }^{23} \\
(1980)\end{array}$ & 74a / fem. & $\begin{array}{l}\text { prótese total em resi- } \\
\text { na acrílica termopoli- } \\
\text { merizável }\end{array}$ & $\begin{array}{l}\text { inflamação e descola- } \\
\text { mento da mucosa do } \\
\text { palato }\end{array}$ & $\begin{array}{c}\text { MMA } \\
\text { (teste de contato) }\end{array}$ & $\begin{array}{l}\text { prótese confecciona- } \\
\text { da em ciclo completo } \\
\text { de polimerização }\end{array}$ \\
\hline $\begin{array}{c}\text { McCabe, Basker }{ }^{54} \\
(1976)\end{array}$ & $\begin{array}{l}\text { 67a / fem. } \\
55 a / \text { fem. }\end{array}$ & $\begin{array}{l}\text { prótese total em resi- } \\
\text { na acrílica termopoli- } \\
\text { merizável }\end{array}$ & $\begin{array}{l}\text { ardência em mucosa } \\
\text { edema bucal, dificul- } \\
\text { dade para deglutir }\end{array}$ & MMA & $\begin{array}{l}\text { confecção de nova } \\
\text { prótese com menor } \\
\text { conteúdo de } \\
\text { metilmetacrilato }\end{array}$ \\
\hline $\begin{array}{c}\text { Giunta, Zablotsky }{ }^{26} \\
\text { (1976) }\end{array}$ & $24 a$ / fem. & $\begin{array}{l}\text { prótese parcial fixa } \\
\text { de três elementos } \\
\text { em resina acrílica } \\
\text { autopolimerizável }\end{array}$ & $\begin{array}{c}\text { dificuldade para } \\
\text { deglutir e lesões } \\
\text { brancas próximas à } \\
\text { prótese }\end{array}$ & $\begin{array}{c}\text { MMA } \\
\text { (teste de contato) }\end{array}$ & $\begin{array}{l}\text { ciclo em autoclave ou } \\
\text { imersão em água por } \\
\text { ao menos } 36 \text { horas } \\
\text { (teste de contato } \\
\text { negativo) }\end{array}$ \\
\hline $\begin{array}{c}\text { Nealey, Del Rio }{ }^{59} \\
\text { (1969) }\end{array}$ & 40a / fem. & $\begin{array}{c}\text { prótese parcial } \\
\text { temporária em resina } \\
\text { acrílica autopolime- } \\
\text { rizável }\end{array}$ & $\begin{array}{l}\text { ardência e prurido } \\
\text { locais, edema nos } \\
\text { olhos e lábios }\end{array}$ & $\begin{array}{c}\text { MMA e resina autopo- } \\
\text { limerizável } \\
\text { (teste de contato) }\end{array}$ & $\begin{array}{c}\text { utilização de resina } \\
\text { acrílica termopolime- } \\
\text { rizável }\end{array}$ \\
\hline
\end{tabular}

QUADRO 4 - Compilação dos dados de casos de sensibilidade/reação alérgica à resina acrílica relatados na literatura (Fonte: GONÇALVES ${ }^{27}$, 2005).

\section{Resinas compostas}

A presença de monômeros não polimerizados, oriundos das resinas compostas utilizadas durante os procedimentos de colagem ortodôntica, também pode ser considerada fator etiológico no aumento da frequência das reações imunológicas adversas em Ortodontia. Assim como ocorre com as resinas acrílicas, a reação de polimerização das resinas compostas pode permanecer incompleta por tempo indefinido, logo, moléculas de monômero livre de trietileno glicol metacrilato (TEGDMA) ou 2-hidroxi-etil-metacrilato (HEMA) podem ser diretamente responsáveis pelas reações de citotoxicidade e hipersensibilidade ocasionadas 
por esse material. Nesse aspecto, pode-se ressaltar o contato dos tecidos gengivais com os primers de colagem, compostos essencialmente por monômeros não-polimerizados, que pode levar a um aspecto inflamatório gengival (Fig. 5). Vande Vannet e Hanssens ${ }^{83}$ comprovaram que os primers apresentam alta toxicidade quando comparados às resinas de colagem de acessórios ortodônticos previamente polimerizadas.

Quando avaliada a citotoxicidade das resinas compostas para colagem ortodôntica através do teste MTT, Nocca et al. ${ }^{61}$ demonstraram que as resinas fotopolimerizáveis apresentaram menor potencial citotóxico, quando comparadas às autopolimerizáveis. Dessa maneira, além das vantagens clínicas, as resinas fotopolimerizáveis apresentam também maior biocompatibilidade.

\section{Quais as atitudes frente à constatação de alergia a algum produto odontológico?}

De maneira geral, deve-se encaminhar o paciente ao médico (alergista ou dermatologista) e evitar a exposição ao material irritante. Outras condutas recomendáveis discutidas no presente trabalho estão resumidas no quadro 5.

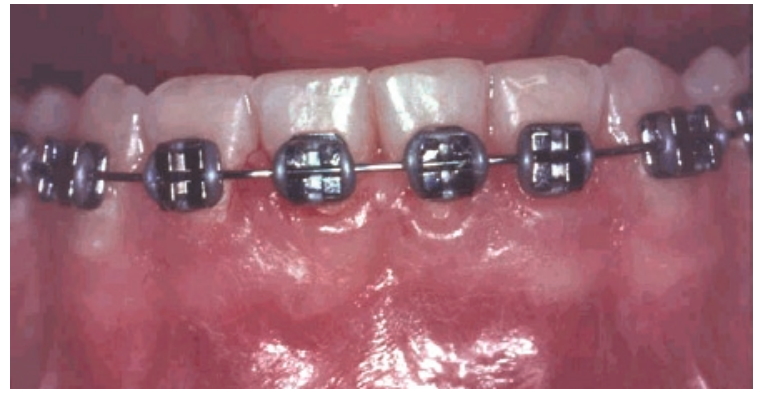

FIGURA 5 - Aspecto inflamatório gengival pelo contato com resina de colagem.

\section{CONSIDERAÇÕES FINAIS}

Diante do exposto, conclui-se que é de fundamental importância o conhecimento por parte do ortodontista sobre a composição dos materiais que utiliza na sua rotina clínica, bem como a possibilidade dos mesmos ocasionarem reações a si mesmo e aos seus pacientes. Frente à ocorrência de uma reação alérgica, o profissional deve ter condições de dar o devido suporte e encaminhamento a tal situação, trabalhando em conjunto com áreas associadas, especialmente a Dermatologia, oferecendo ao paciente a melhor solução. Nesse aspecto, é de grande valia a proposição de materiais alternativos, priorizando a saúde geral do paciente.

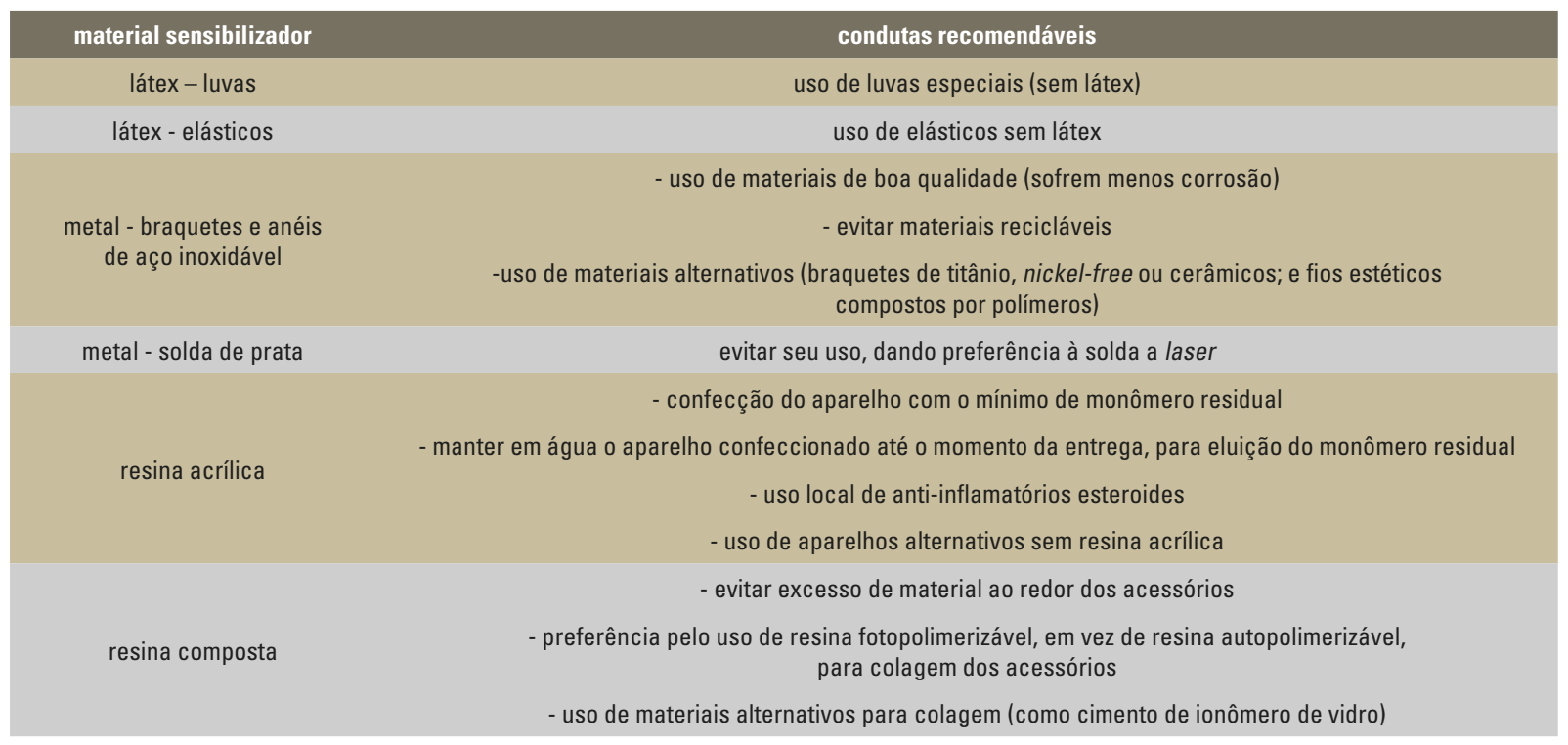

QUADRO 5 - Resumo das condutas recomendáveis em caso de alergia aos diferentes materiais ortodônticos. 


\title{
Biocompatibility of orthodontic materials: myth or reality?
}

\author{
Abstract \\ The aim of this paper is to present a review on the biocompatibility of orthodontic materials. Hypersensitivity reac- \\ tions to these materials are discussed and the recommended conduct in this kind of situation are presented.
}

Keywords: Orthodontics. Biocompatibility. Hypersensitivity. Allergy. Orthodontic materials.

\section{REFERÊNCIAS}

1. AMERICAN DENTAL ASSOCIATION. Standards and standards administration. 2009: Disponivel em: <http://www.ada.org/ prof/resources/standards/index.asp>. Acesso em: 22 jan. 2008

2. WORKSHOP: biocompatibility of metals in dentistry. National Institute of Dental Research. J. Am. Dent. Assoc., Chicago, v. 109 , no. 3, p. $469-471,1984$

3. AL-WAHEIDI, E. M. Allergic reaction to nickel orthodontic wires: a case report. Quintessence Int., Berlin, v. 26, no. 6, p. 385-387, 1995

4. ANUSAVICE, K. J. Phillip's Science of Dental Materials. 10th ed. Philadelphia: WB Saunders, 1996.

5. AUSTIN, A. T.; BASKER, R. M. The level of residual monomer in acrylic denture base materials with particular reference to a modified method of analysis. Br. Dent. J., London, v. 149 no. 10 , p. $281-286,1980$.

6. AUZERIE, V. et al. Oral lichenoid eruption due to methacrylate allergy. Contact Dermat., Copenhagen, v. 45, no. 4, p. 241, 2001.

7. BAKER, S.; BROOKS, S. C.; WALKER, D. M. The release of residual monomeric methyl methacrylate from acrylic appliances in the human mouth: an assay for monomer in saliva. J. Dent. Res., Alexandria, v. 67, no. 10, p. 1295-1299, 1988.

8. BARRETT, R. D.; BISHARA, S. E.; QUINN, J. K. Biodegradation of orthodontic appliances. Part l. Biodegradation of nickel and chromium in vitro. Am. J. Orthod. Dentofacial Orthop., St. Louis, v. 103, no. 1, p. 8-14, 1993.

9. BARTON, E. C. Latex allergy: recognition and management of a modern problem. Nurse Pract., Springhouse, v. 18, no. 11, p. $54-58,1993$.

10. BASS, J. K.; FINE, H.; CISNEROS, G. J. Nickel hypersensitivity in the orthodontic patient. Am. J. Orthod. Dentofacial Orthop., St. Louis, v. 103, no. 3, p. 280-285, 1993.

11. BERGMAN, B. et al. The distribution of nickel in mice. An autoradiographic study. J. Oral Rehabil., Oxford, v. 7, no. 4 p. 319-324, 1980

12. BISHARA, S. E. Oral lesions caused by an orthodontic retainer: a case report. Am. J. Orthod. Dentofacial Orthop., St. Louis, v. 108 , no. 2, p. 115-117, 1995.

13. BLANCO-DALMAU, L.; CARRASOUILLO-ALBERTY, H.; SILVAPARRA, J. A study of nickel allergy. J. Prosthet. Dent., St. Louis, v. 52, no. 1, p. 116-119, 1984.

14. BURKE, F. J.; WILSON, N. H. Allergic reactions to rubber gloves in dental patients. Br. Dent. J., London, v. 173, no. 4, p. 124, 1992.

15. CONDE-SALAZAR, L. et al. Type IV allergy to rubber additives: a 10 -year study of 686 cases. J. Am. Acad. Dermatol., St. Louis, v. 29, no. 2, Pt. 1, p. 176-180, 1993.
16. COUNTS, A. L. et al. Nickel allergy associated with a transpalatal arch appliance. J. Orofac. Orthop., München, v. 63, no. 6, p. $509-515,2002$

17. DE SILVA, B. D.; DOHERTY, V. R. Nickel allergy from orthodontic appliances. Contact Dermat., Copenhagen, v. 42 no. 2 , p. $102-103,2000$

18. DEVLIN, H.; WATTS, D. C. Acrylic 'allergy'? Br. Dent. J., London, v. 157 , no. 8, p. 272-275, 1984.

19. DOLCl, G. S. et al. Biodegradação de braquetes ortodônticos: avaliação da liberação iônica in vitro. Rev. Dental Press Ortodon. Ortop. Facial, Maringá, v. 13, n. 3, p. 77-84, 2008.

20. ESTRELA, C. Metodologia científica. 2. ed. São Paulo: Artmed, 2005.

21. FACCIONI, F. et al. In vivo study on metal release from fixed orthodontic appliances and DNA damage in oral mucosa cells. Am. J. Orthod. Dentofacial Orthop., St. Louis, v. 124, no. 6, p. 687-693, 2003.

22. FEASBY, W. H.; ECCLESTONE, E. R.; GRAINGER, R. M. Nickel sensitivity in pediatric dental patients. Pediatr. Dent., Chicago, v. 10, no. 2, p. 127-129, 1988.

23. FERNSTRÖM, A. I.; ÖQUIST, G. Location of the allergenic monomer in warm-polymerized acrylic dentures. Part I: Causes of denture sore mouth, incidence of allergy, different allergens and test methods on suspicion of allergy to denture material - a survey of the literature. Case report, allergenic analysis of denture and test casting. Swed. Dent. J., Jönköping, v. 4, no. 6, p. 241-252, 1980

24. FISHER, A. A. Allergic contact reactions in health personnel. J. Allergy Clin. Immunol., St. Louis, v. 90, no. 5, p. 729-738, 1992.

25. FREITAS, M. P. M. Toxicidade da solda de prata utilizada em Ortodontia: estudo in vitro e in situ. 2008. Tese (Doutorado)Pontifícia Universidade Católica do Rio Grande do Sul, Porto Alegre, 2008.

26. GIUNTA, J.; ZABLOTSKY, N. Allergic stomatitis caused by selfpolymerizing resin. Oral Surg. Oral Med. Oral Pathol., St. Louis, v. 41, no. 5, p. 631-637, 1976.

27. GONÇALVES, T. S. Avaliação in situ do monômero residual e da rugosidade superficial de resina acrílica autopolimerizável. 2005. Dissertação (Mestrado)-Pontifícia Universidade Católica do Rio Grande do Sul, Porto Alegre, 2005.

28. GONCALVES, T. S.; MENEZES, L. M.; SILVA, L. E. Residual monomer of autopolymerized acrylic resin according to different manipulation and polishing methods: an in situ evaluation. Angle Orthod., Appleton, v. 78, no. 4, p. 722-727, 2008. 
29. GONÇALVES, T. S. et al. Cytotoxicity of two autopolymerized acrylic resins used in Orthodontics. Angle Orthod., Appleton, v. 78 , no. 5 , p. $926-930,2008$.

30. GONÇALVES, T. S. et al. Allergy to auto-polymerized acrylic resin in an orthodontic patient. Am. J. Orthod. Dentofacial Orthop., St. Louis, v. 129, no. 3, p. 431-435, 2006.

31. GRIMAUDO, N. J. Biocompatibility of nickel and cobalt dental alloys. Gen. Dent., Chicago, v. 49, no. 5, p. 498-503, 504-495, 2001.

32. GRIMSDOTTIR, M. R.; GJERDET, N. R.; HENSTEN-PETTERSEN, A. Composition and in vitro corrosion of orthodontic appliances. Am. J. Orthod. Dentofacial Orthop., St. Louis, v. 101, no. 6, p. 525-532, 1992.

33. HAMULA, D. W.; HAMULA, W.; SERNETZ, F. Pure titanium orthodontic brackets. J. Clin. Orthod., Boulder, v. 30, no. 3, p. 140-144, 1996.

34. HUANG, F. M. et al. Cytotoxic effects of denture base materials on a permanent human oral epithelial cell line and on primary human oral fibroblasts in vitro. Int. J. Prosthodont., Lombard, v. 14, no. 5, p. 439-443, 2001.

35. HUANG, T. H.; YEN, C. C.; KAO, C. T. Comparison of ion release from new and recycled orthodontic brackets. Am. J. Orthod. Dentofacial Orthop., St. Louis, v. 120, no. 1, p. $68-75,2001$

36. HUGGETT, R.; BROOKS, S. C.; BATES, J. F. The effect of different curing cycles on levels of residual monomer in acrylic resin denture base materials. Quintessence Dent. Technol., Chicago, v. 8, no. 6, p. 365-371, 1984.

37. JANSON, G. R. et al. Nickel hypersensitivity reaction before, during, and after orthodontic therapy. Am. J. Orthod. Dentofacial Orthop., St. Louis, v. 113, no. 6, p. 655-660, 1998.

38. JONES, T. K. et al. Dental implications of nickel hypersensitivity. J. Prosthet. Dent., St. Louis, v. 56, no. 4, p. 507-509, 1986.

39. KALIMO, K.; MATTILA, L.; KAUTIAINEN, H. Nickel allergy and orthodontic treatment. J. Eur. Acad. Dermatol. Venereol., Amsterdam, v. 18, no. 5, p. 543-545, 2004.

40. KAO, C. T. et al. The cytotoxicity of orthodontic metal bracket immersion media. Eur. J. Orthod., Oxford, v. 29, no. 2, p.198-203, 2007.

41. KEDJARUNE, U.; CHAROENWORALUK, N. KOONTONGKAEW, S. Release of methyl methacrylate from heat-cured and autopolymerized resins: cytotoxicity testing related to residual monomer. Aust. Dent. J., Sydney, v. 44, no. 1, p. 25-30, 1999.

42. KEROSUO, H.; KANERVA, L. Systemic contact dermatitis caused by nickel in a stainless steel orthodontic appliance. Contact Derm., Copenhagen, v. 36, no. 2, p. 112-113, 1997.

43. KEROSUO, H. et al. Nickel allergy in adolescents in relation to orthodontic treatment and piercing of ears. Am. J. Orthod. Dentofacial Orthop., St. Louis, v. 109, no. 2, p. 148-154, 1996.

44. KEROSUO, H.; MOE, G.; KLEVEN, E. In vitro release of nickel and chromium from different types of simulated orthodontic appliances. Angle Orthod., Applenton, v. 65, no. 2, p. 111-116, 1995.

45. KLASSEN, C. Toxicology: the basic science of poisons. 5th ed. New York: Mc Graw-Hill, 1996.

46. KOUTIS, D.; FREEMAN, S. Allergic contact stomatitis caused by acrylic monomer in a denture. Australas. J. Dermatol., Sydney, v. 42, no. 3, p. 203-206, 2001.

47. LAI, Y. L. et al. Cytotoxic effects of dental resin liquids on primary gingival fibroblasts and periodontal ligament cells in vitro. J. Oral Rehabil., Oxford, v. 31, no. 12, p. 1165-1172, 2004.

48. LAMB, D. J.; ELLIS, B.; PRIESTLEY, D. Loss into water of residual monomer from autopolymerizing dental acrylic resin. Biomaterials, Guilford, v. 3, no. 3, p. 155-159, 1982.

49. LEE, S. Y.; LAI, Y. L.; HSU, T. S. Influence of polymerization conditions on monomer elution and microhardness of autopolymerized polymethyl methacrylate resin. Eur. J. Oral Sci., Copenhagen, v. 110, no. 2, p. 179-183, 2002

50. LEVY, D. A. et al. Allergy to latex. Allergy, Copenhagen, v. 47, no. 6, p. 579-587, 1992.
51. LUNDER, T.; ROGL-BUTINA, M. Chronic urticaria from an acrylic dental prosthesis. Contact Derm., Copenhagen, v. 43, no. 4, p. 232-233, 2000.

52. MANCUSO, G.; BERDONDINI, R. M. Eyelid dermatitis and conjunctivitis as sole manifestations of allergy to nickel in an orthodontic appliance. Contact Derm., Copenhagen, v. 46, no. 4, p. 245, 2002.

53. MATOS DE SOUZA, R.; MACEDO DE MENEZES, L. Nickel, chromium and iron levels in the saliva of patients with simulated fixed orthodontic appliances. Angle Orthod., Appleton, v. 78, no. 2, p. 345-350, 2008.

54. MCCABE, J. F.; BASKER, R. M. Tissue sensitivity to acrylic resin: a method of measuring the residual monomer content and its clinical application. Br. Dent. J., London, v. 140, no. 10, p. 347-350, 1976.

55. MENEZES, L. M. et al. Hypersensitivity to metals in Orthodontics. Am. J. Orthod. Dentofacial Orthop., St. Louis, v. 126, no. 1, p. 58-64, 2004.

56. MENEZES, L. M.; SOUZA, F. L.; BOLOGNESE, A. M.; CHEVITARESE, O. Reação alérgica em paciente ortodôntico: um caso clínico. Ortodontia Gaúcha, Porto Alegre, v. 1, n. 1, p. 51-56, 1997

57. MOFFA, J. P. Biological effects of nickel-containing dental alloys. Council on Dental Materials, Instruments, and Equipment. J. Am. Dent. Assoc., Chicago, v. 104, no. 4, p. 501-505, 1982.

58. MUNKSGAARD, E. C. Toxicology versus allergy in restorative dentistry. Adv. Dent. Res., Washington, D. C., v. 6, p. 17-21, 1992.

59. NEALEY, E. T.; DEL RIO, C. E. Stomatitis venenata: reaction of a patient to acrylic resin. J. Prosthet. Dent., St. Louis, v. 21, no. 5, p. 480-484, 1969.

60. NIELSEN, N. H. et al. Incidence of allergic contact sensitization in Danish adults between 1990 and 1998; the Copenhagen Allergy Study, Denmark. Br. J. Dermatol., Oxford, v. 147, no. 3, p. 487-492, 2002.

61. NOCCA, G. et al. In vitro comparison of the cytotoxicity of two orthodontic composite resins. Minerva Stomatol., Torino, v. 55, no. 5, p. 297-305, 2006.

62. NUNES DE MELLO, J. A. et al. Reducing the negative effects of chemical polishing in acrylic resins by use of an additional cycle of polymerization. J. Prosthet. Dent., St. Louis, v. 89, no. 6, p. 598-602, 2003.

63. MATASA, C. G. Trend: good bye Ni, welcome Co, Mn. The Orthod. Mater. Insider, [s.I.], v. 8, n. 4, p. 1-6. Dec. 1995.

64. PARK, H. Y.; SHEARER, T. R. In vitro release of nickel and chromium from simulated orthodontic appliances. Am. J. Orthod., St. Louis, v. 84, no. 2, p. 156-159, 1983.

65. RICKLES, N. H. Allergy in surface lesions of the oral mucosa. Oral Surg. Oral Med. Oral Pathol., St. Louis, v. 33, no. 5, p. 744-754, 1972.

66. RIESGO, O. V. S. M.; DUFFO, G. S. Galvanic corrosion in orthodontic appliances. J. Dent. Res., Alexandria, v. 75, no. 5, p. 1063, 1996.

67. ROSE, E. C. et al. Contribution to the biological assessment of orthodontic acrylic materials: measurement of their residual monomer output and cytotoxicity. J. Orofac. Orthop., München, v. 61, no. 4, p. 246-257, 2000.

68. RUIZ-GENAO, D. P. et al. Labial edema due to an acrylic dental prosthesis. Contact Derm., Copenhagen, v. 48, no. 5, p. 273-274, 2003.

69. SADAMORI, S. et al. A method of determining residual monomer in acrylic resin using methyl ethyl ketone. Aust. Dent. J., Sydney, v. 35, no. 6, p. 509-513, 1990.

70. SCHMALZ, G.; BROWNE, R. M. The biological evaluation of medical devices used in dentistry: the influence of the European Union on the preclinical screening of dental materials. Int. Dent. J., London, v. 45, no. 4, p. 275-278, 1995.

71. SCHRIVER, W. R. et al. Allergic response to stainless steel wire. Oral Surg. Oral Med. Oral Pathol., St. Louis, v. 42, no. 5, p. 578-581, 1976. 
72. SCHUSTER, G. et al. Allergies induced by orthodontic alloys: incidence and impact on treatment. Results of a survey in private orthodontic offices in the Federal State of Hesse,

Germany. J. Orofac. Orthop., München, v. 65, no. 1, p. 48-59, 2004.

73. SHEPHERD, G. M. Safe use of latex rubber. Ann. Intern. Med., Philadelphia, v. 123, no. 3, p. 234-235, 1995.

74. SÓRIA, M. L. et al. Avaliação in vitro da liberação de níquel por braquetes metálicos. Rev. Dental Press Ortodon. Ortop. Facial, Maringá, v. 10, p. 87-96, 2005.

75. STAFFOLANI, N. et al. Ion release from orthodontic appliances. J. Dent., Bristol, v. 27, no. 6, p. 449-454, 1999.

76. STAFFORD, G. D.; BROOKS, S. C. The loss of residual monomer from acrylic orthodontic resins. Dent. Mater, Copenhagen, v. 1, no. 4, p. 135-138, 1985.

77. STENMAN, E.; BERGMAN, M. Hypersensitivity reactions to dental materials in a referred group of patients. Scand. J.

Dent. Res., Copenhagen, v. 97, no. 1, p. 76-83, 1989.

78. TANG, L.; EATON, J. W. Inflammatory responses to biomaterials. Am. J. Clin. Pathol., Chicago, v. 103, no. 4, p. 466-471, 1995

79. TANOUE, N.; NAGANO, K.; MATSUMURA, H. Use of a light-polymerized composite removable partial denture base for a patient hypersensitive to poly(methyl methacrylate), polysulfone, and polycarbonate: a clinical report. J. Prosthet. Dent., St. Louis, v. 93, no. 1, p. 17-20, 2005

80. TOMS, A. P. The corrosion of orthodontic wire. Eur. J. Orthod. London, v. 10, no. 2, p. 87-97, 1988

81. TSUCHIYA, H. et al. Leaching and cytotoxicity of formaldehyde and methyl methacrylate from acrylic resin denture base materials. J. Prosthet. Dent., St. Louis, v. 71, no. 6 , p. 618-624, 1994

82. VALLITTU, P. K. The effect of surface treatment of denture acrylic resin on the residual monomer content and its release into water. Acta Odontol. Scand., Oslo, v. 54, no. 3 p. 188-192, 1996.
83. VANDE VANNET, B. M. HANSSENS, J. L. Cytotoxicity of two bonding adhesives assessed by three-dimensional cell culture. Angle Orthod., Appleton, v. 77, no. 4, p. 716-722, 2007.

84. WATAHA, J. C. Biocompatibility of dental casting alloys: a review. J. Prosthet. Dent., St. Louis, v. 83, no. 2, p. 223-234 2000.

85. WATAHA, J. C. et al. Effect of toothbrushing on the toxicity of casting alloys. J. Prosthet. Dent., St. Louis, v. 87 , no. 1 , p. 94-98, 2002.

86. WATAHA, J. C.; LOCKWOOD, P. E.; SCHEDLE, A. Effect of silver, copper, mercury, and nickel ions on cellular proliferation during extended, low-dose exposures. J. Biomed. Mater. Res., Hoboken, v. 52, no. 2, p. 360-364, 2000

87. WATAHA, J. C.; MESSER, R. L. Casting alloys. Dent. Clin. North Am., Philadelphia, v. 48, no. 2, p. 7-8, 499-512, 2004.

88. WEISS, M. E.; HIRSHMAN, C. A. Latex allergy. Can. J. Anaesth., Toronto, v. 39, no. 6, p. 528-532, 1992.

89. WESTPHALEN, G. H. Avaliação de hipersensibilidade a metais e toxicidade genética associadas ao uso de aparelhos ortodônticos fixos. 2006. Dissertação (Mestrado)Pontifícia Universidade Católica do Rio Grande do Sul, Porto Alegre, 2006.

90. WESTPHALEN, G. H. et al. In vivo determination of genotoxicity induced by metals from orthodontic appliances using micronucleus and comet assays. Genet. Mol. Res. Ribeirão Preto, v. 7, n. 4, p. 1259-1266, 2008.

91. YILMAZ, $H$. et al. The effect of glass fiber reinforcement on the residual monomer content of two denture base resins. Quintessence Int., Berlin, v. 34, no. 2, p. 148-153, 2003.

92. YUNUS, N.; HARRISON, A.; HUGGETT, R. Effect of microwave irradiation on the flexural strength and residual monomer levels of an acrylic resin repair material. J. Oral Rehabil., Oxford v. 21 , no. 6 , p. $641-648,1994$
Endereço para correspondência

Luciane Macedo de Menezes

Faculdade de Odontologia da PUCRS

Av. Ipiranga, 6681 - Prédio 6 - Sala 209

CEP: $90.619-900$ - Porto Alegre/RS

E-mail: luciane@portoweb.com.br 